Even as written communication is important, spoken communication has been assuming an increasing role. We are called on to speak in such media as videos, teleconferences, and podcasts. Our ability to speak clearly is as important as our ability to formulate our arguments concisely and clearly.

Phil Yaffe, who has provided advice to Ubiquity readers on how to write clearly and concisely, offers advice on how to speak clearly.

Peter Denning

Editor

\title{
How to Rapidly Improve Speaking Skills
}

\author{
by Philip Yaffe
}

\begin{abstract}
Most scientists and technologist today recognize the need to write well in order to better convey what they do to colleagues, managers, administrators, and the general public. But how about oral skills? After all, we spend much more time speaking than we do writing.
\end{abstract}

I am referring not only to giving formal speeches and presentations, but also informal encounters such as talking on the telephone, discussing ideas with colleagues, attending meetings, participating in seminars and workshops, or simply socializing after work.

The fact is, most people speak very poorly. I know, because I used to be a very poor speaker. Now I speak very well, at least that is what everyone tells me. My change from being a poor speaker to being a good speaker happened virtually overnight. I admit that I had a head start because I was already a pretty good writer, so I already knew how to cogently organize content. But delivering it orally was quite a different matter.

Here's the story.

I was a student at UCLA in the 1960s. After graduating, I spent two years as a Peace Corps volunteer in Tanzania, East Africa. When I got there, of course everything was quite different from anything I had previously experienced. For one thing, I was posted to a tiny bush village next to what was supposed to be a major north-south road. Anything beyond 20 cars per day passing by was considered to be heavy traffic; in Los Angeles, less than 20 cars per minute was considered to be abnormally low traffic.

Perhaps the biggest surprise occurred when I turned on my shortwave radio. I quickly found the frequencies for both the BBC (British Broadcasting Corporation) and the Voice of America. The difference was astounding.

Listening to the BBC, I heard cashiers, janitors, parking attendants, etc., speaking as if they had graduated from prestigious universities. By contrast, listening to Voice of America, I heard people at the top of the educational and social ladder speaking as if they had never even graduated from primary school.

This was no chance occurrence; it happened every time I turned on the radio. "How is it that high-level Americans seem to speak less well than low level Brits?" I kept asking myself. And found no answer.

After a few weeks I came to a startling conclusion. The apparent superiority of the Brits had nothing to do with either intelligence or education. It was in fact physical.

If you pay attention, you will notice that the British, particularly the English, tend to form their words on their lips, while Americans form them in the throat. This phenomenon is particularly noticeable among males, whose deep, gravely voice is considered to be masculine, virile and seductive.

I believe that forming words in the throat puts abnormal strain on the larynx, which is why Americans so often tend to stumble over their words. They frequently interrupt their speech with interjections such as "um", "ah", and other irritating hesitations. This is not because they don't know what to say next. It's because they are giving their vocal cords a momentary chance to recover.

To put the idea to the test, I consciously began forming my words on my lips rather than in the throat. My own irritating hesitations (I was notorious for this) vanished almost overnight. Suddenly I could put together a sentence that flowed fluently from one end to the other. In fact, I could put together whole series of sentences that flowed fluently from one end to the other with hardly a hesitation in sight. 
Having tested this discovery over several weeks, I decided to purposely redesign my articulation. It wasn't easy. I had to consciously think about how I was forming my words virtually every minute of the day. However, after a couple of weeks it began feeling more and more natural, until finally it was.

All this happened 40 years ago. During the intervening four decades, I have gained somewhat of a reputation as an entertaining and provocative public speaker, not only in English but also in French (I live in Belgium). In short, redesigning my voice has worked extremely well for me. I don't know it if would work for anyone else, but I see no reason why not.

How can you tell if you are a throat speaker or a lip speaker? Here are a couple of simple tests.

First, put the fingers of one hand on your throat when you speak. If you can feel your vocal cords vibrating, then you are definitely a throat speaker. However, this is not definitive; you can still be a throat speaker without actually feeling the physical effect.

If the fingers-to-the-throat test fails, record your voice. If you sound anything like John Wayne or Jimmy Stewart (I'm not certain what the female equivalent would be), you could probably benefit from redesigning your articulation.

How?

Read a text aloud in your normal voice; then read it aloud again with a slightly higher pitch and exaggerated movements of your lips. You should hear a difference. Do this a few more times to be certain you hear a difference. Then start again with the same slightly higher pitch but less exaggerated lip movements. After a few tries, you should find a combination of pitch and lip movements that feels relatively comfortable.

From then on, each day try to use your new voice more and more frequently. It won't take too long before it will feel completely natural and you will find yourself using it all the time. I haven't used my "real" voice (i.e. the one I grew up with) in over four decades.

But two words of warning.

First, sounding better does not ipso facto make you a better speaker; it just makes you more listenable. As with writing, the real test of good speaking is what you say, i.e. content, rather than how you say it. If your ideas are ill formed and incoherent, no matter how well you express them, they will still fail to convince.

Secondly, if you do decide to make the change, you are likely to develop a pseudo "Oxbridge" English accent. This is quite normal; forming words on the lips naturally gives rise to this type of accent. However, out of context it can be rather embarrassing.

Since I was living with a lot of British expatriates in Tanzania, my new way of speaking didn't seem particularly odd. However, the minute I returned to Los Angeles, people began commenting on it, including my mother. "Where did you pick up that snooty accent? Get rid of it." So I did. I found a middle ground between the two accents. You can too.

If you are serious about improving your speaking, here's a tip. Why not join a local chapter of Toastmasters International? Toastmasters is a worldwide club of people in all walks of life dedicated to helping each other improve their orals skills. Participating is inexpensive, painless, and a lot of fun (http://www.toastmasters.org).

Philip Yaffe is a former reporter/feature writer with The Wall Street Journal and a marketing communication consultant. He currently teaches a course in good writing and good speaking in Brussels, Belgium. His recently published book In the "I" of the Storm: the Simple Secrets of Writing \& Speaking (Almost) like a Professional is available from Story Publishers in Ghent, Belgium (http://www.storypublishers.be/) and Amazon (http://www.amazon.com).

For further information, contact:

Philip Yaffe

Brussels, Belgium

Tel: $\quad+32(0) 26600405$

Email: phil.yaffe@yahoo.com, phil.yaffe@gmail.com 